Preface

\title{
Thrombosis and Hemostasis Related Issues in Women and Pregnancy
}

\author{
Maha Othman, MD, MSc, PhD ${ }^{1}$ Claire McLintock, MBChB(Edin), FRACP, FRCPA ${ }^{2}$ \\ Rezan Kadir, MBChB, MRCOG, FRCS(Ed), MD 3 \\ 1 Department of Biomedical and Molecular Sciences, School of \\ Medicine, Queen's University, Kingston, Ontario, Canada \\ ${ }^{2}$ Division of Maternal-Fetal Medicine, National Women's Health, \\ Auckland City Hospital, Auckland, New Zealand \\ ${ }^{3}$ Department of Obstetrics and Gynaecology, Katharine Dormandy \\ Haemophilia and Thrombosis Centre, The Royal Free Hospital, \\ Hampstead, London, United Kingdom \\ Semin Thromb Hemost 2016;42:693-695.
}

Normal pregnancy is associated with major physiological alterations in the coagulation and fibrinolytic systems that aim to maintain placental function and prevent excessive bleeding at delivery. ${ }^{1}$ These alterations mostly promote a procoagulant state and thus unfortunately enhance the risk of thromboembolism. There is an estimated 4.5-fold increase in thrombotic risk throughout gestation and the postpartum period, ${ }^{2,3}$ and 22-fold risk in the 6 weeks period following delivery. ${ }^{4}$ Pulmonary embolism remains the leading cause of direct maternal deaths in developed countries and accounts for approximately $20 \%$ of pregnancy-related deaths. ${ }^{5}$

On the contrary, inherited bleeding disorders can lead to life-threatening hemorrhage during pregnancy and in the postpartum period. ${ }^{6,7}$ Postpartum hemorrhage (PPH) is associated with substantial maternal morbidity and continues to also be a leading cause of maternal mortality worldwide with a prevalence rate of approximately $6 \%,{ }^{8}$ with severe obstetric hemorrhage now identified in $1.1 \%$ women. ${ }^{9}$

The correct diagnosis and management of hemostaticrelated disorders of pregnancy require appropriate laboratory testing. This is challenged by two major issues: first is that most normal values shift during pregnancy and peurpurium ${ }^{10,11}$; a problem that is complicated by the lack of available sensitive tests and also the poor applicability and interpretation-at times-of some of these hemostatic tests. The second issue is that conventional routine assays of hemostasis, which most laboratories and thus clinicians rely on, are insufficient to represent the in vivo conditions, making it difficult to assess some complex pregnancy hemostatic complications. ${ }^{12,13}$

This issue of Seminars in Thrombosis \& Hemostasis is therefore devoted to thrombosis and hemostasis issues

Address for correspondence Maha Othman, MD, MSc, PhD, Department of Biomedical and Molecular Sciences, School of Medicine, Queen's University, Kingston, ON K7L 3N6, Canada (e-mail: othman@queensu.ca).
Issue Theme Thrombosis and Hemostasis Related Issues in Women and Pregnancy; Guest Editors: Maha Othman, MD, MSc, $\mathrm{PhD}$, Claire McLintock, $M B C h B(E d i n)$, FRACP, FRCPA, and Rezan Kadir, MBChB, MRCOG, FRCS(Ed), MD.

related to women and, in particular, to pregnancy. Due to the wide spectrum of potential disorders, we have focused on some selected seasoned-currently hot-topics. A review of the diagnostic challenges and current treatment of each of these disorders will be provided, together with the recently available recommendations and guidelines for better management.

To begin with, and in the first article of this issue, Fazoil et $\mathrm{al}^{14}$ provide a comprehensive state-of-the-art review of the molecular changes in the hemostatic system in normal pregnancy and also in association with pregnancy complications. A rich discussion of the various classic and global assays, which supports diagnosis of pregnancy-related hemostatic complications, is also provided. The authors also describe the potential future applications and suitability of these assays to match evolving needs.

von Willebrand disease (VWD) is estimated to affect 0.01 to $1.3 \%$ of the general population, making it the most common inherited mild bleeding disorder. Women with VWD require specific considerations during pregnancy and puerperium. In the second article, Reynen and James ${ }^{15}$ provide a review of evidence and the expert opinion of the management of VWD with pregnancy, in light of the lack of high-quality evidence supporting monitoring and treatment of this disorder. The reported high risk of PPH when von Willebrand factor ristocetin cofactor or factor VIII levels fall below $0.50 \mathrm{IU} / \mathrm{mL}$ and even when aiming for levels $>0.50$ to $1 \mathrm{IU} / \mathrm{mL}$ suggests that a higher level than recommended by current guidelines may be considered. ${ }^{16}$ This article also discusses issues associated with pregnancy in women with VWD, including analgesia during delivery, risk of PPH, and recommended treatment options for various types of VWD.

Copyright $\odot 2016$ by Thieme Medical Publishers, Inc., 333 Seventh Avenue, New York, NY 10001, USA.

Tel: +1(212) 584-4662.
DOI http://dx.doi.org/ 10.1055/s-0036-1593416. ISSN 0094-6176. 
James et $\mathrm{al}^{17}$ then review in detail patient blood management-an evidence-based, comprehensive, multidisciplinary approach to optimizing the care of patients who might need transfusion in the management of PPH. The authors discuss blood product administration strategies, including the role of the blood bank, the role of massive transfusion protocols, the role of laboratory monitoring, and the role of anesthesia management with the optimal management approach of coagulopathy at the time of PPH.

There is little information in the literature with respect to pregnancy in association with rare bleeding disorders (RBDs) and the management these pregnancies can be challenging. ${ }^{18}$ RBDs can have a wide spectrum of bleeding phenotypes and can be associated with various obstetric complications such as miscarriage, placental abruption and fetal loss, antepartum hemorrhage, and PPH. Despite sharing common features, each of these disorders has unique/variable characteristics and the optimal management usually requires a multidisciplinary approach and individualized plan. ${ }^{19}$

In this issue of Seminars in Thrombosis \& Hemostasis, Davies and Kadir ${ }^{20}$ review the bleeding risk associated with factor XI (FXI) deficiency and discuss management of pregnancy in affected women. The authors recommend a multidisciplinary approach and an individual care plan to prevent bleeding complications. They provide data to support assessment of PPH risk using bleeding history and plasma FXI level, together with the consideration of global tests of hemostasis as an aid to guide provision of appropriate hemostatic prophylaxis for delivery.

Bleeding and thrombotic disorders in the neonate are rare but can have life-long complications. Based on a recent Italian registry, the incidence of neonatal thrombosis is 3.4 to $6.5 / 10,000$ live births, ${ }^{21}$ and among the inherited bleeding disorders, hemophilia appears to be the most common bleeding disorder. ${ }^{22}$ Randomized clinical trials of neonates are lacking and recommendations are often based on small studies, expert opinion, or published guidelines. ${ }^{23}$

The next article by Hanmod et $\mathrm{al}^{24}$ thus reviews the issues and challenges related to neonatal hemostatic disorders. They describe the evolution and physiology of neonatal hemostasis as well as the characteristic features of coagulation and the fibrinolytic system, including the laboratory testing of hemostasis in neonates and then comprehensively discuss the thrombotic and hemorrhagic disorders commonly observed in this age group while also providing the optimal management.

In neonates, more than $90 \%$ of thrombi are catheter related. ${ }^{25,26}$ The next article by van Ommen and Sol ${ }^{27}$ is complementary to the preceding one as it deals with neonatal central venous catheter thrombosis. The authors detail the incidence, risk factors, and diagnostic issues. Since optimal management of this condition is currently unknown, the authors present their proposed approach for appropriate management, which takes into consideration the assessment of the risk-benefit ratio of all available therapeutic options before initiating treatment.

Moving on from bleeding to thrombosis, the subsequent set of articles cover thrombotic disorders rather than bleeding. We begin with the article by Chunilal and Bennett, ${ }^{28}$ which discusses the pregnancy-associated venous thrombo- embolism (PAVTE). This condition continues to be a major cause of maternal morbidity and mortality. ${ }^{29}$ Pulmonary embolism accounts for 20 to $30 \%$ of all PAVTE and is associated with a case fatality rate of $2.4 \%{ }^{30}$ The pathophysiology, comprehensive laboratory testing, and treatment options including various anticoagulant therapies during pregnancy and in the postpartum period are described in detail.

Following a general overview of the management of thrombotic disorders in pregnancy, Scully ${ }^{31}$ discusses thrombotic microangiopathies in the next article, including thrombotic thrombocytopenic purpura and atypical hemolytic uremic syndrome; two clinical conditions with microvascular thrombosis and variable clinical features. The article provides an update on the diagnosis and management of the conditions and details therapeutic options to improve fetal and maternal outcomes.

The next article by Schreiber and Hunt ${ }^{32}$ focuses on pregnancy and antiphospholipid syndrome (APS), due to the presence of antiphospholipid antibodies (aPL). The description of aPL in the revised classification criteria includes lupus anticoagulant, anticardiolipin, and anti- $\beta 2$ glycoprotein-I antibodies, which may occur in the absence of systemic lupus erythematous. ${ }^{33}$ The article details the description of each of these antibodies and the pathogenesis of thrombosis and relation to placental insufficiency, preeclampsia, and fetal loss. The updated standard of care of both thrombotic and obstetric APS is also presented with a recommendation for randomized controlled trials to generate robust evidence for the use of newer therapeutic options.

The next article in this issue of Seminars in Thrombosis \& Hemostasis deals with the use of direct oral anticoagulants (DOACs) in pregnancy. Cohen et al ${ }^{34}$ describe how DOACs are an effective, safe, and convenient therapeutic alternative to warfarin and other vitamin $\mathrm{K}$ antagonists and are now established for a wide range of indications. They explain that the use of this group of drugs requires special consideration in relation to fertility, pregnancy, and lactation in women of reproductive age, and with respect to the bleeding risk and complications.

The final article by D'Souza et $\mathrm{al}^{35}$ is on optimal anticoagulation for pregnant women with mechanical heart valves. The lack of high-quality data from prospective studies makes the choice of the optimal method of anticoagulation challenging. A discussion of the particular risks and benefits with each of three available therapeutic strategies is given in light of competing maternal and fetal adverse-event profiles. The authors conclude that a multidisciplinary team, including hematologists, cardiologists, obstetric physicians, and highrisk obstetricians with expertise in the management of pregnant women with cardiac disease, is required to optimize outcomes.

We sincerely thank all the contributors to this special issue of Seminars in Thrombosis \& Hemostasis for their excellent contributions and collaboration during the production of this issue and on behalf of all the contributors, I sincerely wish that you, the reader, enjoy this selection of topics around thrombotic and hemorrhagic issues related to pregnancy. With this, we hope you stay up to date with the state-of-the-art 
diagnosis and management of these issues and you become familiar with current expert opinions and best practices to improve maternal and fetal outcomes, for the betterment of your clinical and research work.

\section{References}

1 Stirling Y, Woolf L, North WR, Seghatchian MJ, Meade TW. Haemostasis in normal pregnancy. Thromb Haemost 1984;52(2):176-182

2 Heit JA, Kobbervig CE, James AH, Petterson TM, Bailey KR, Melton LJ III. Trends in the incidence of venous thromboembolism during pregnancy or postpartum: a 30-year population-based study. Ann Intern Med 2005;143(10):697-706

3 Pomp ER, Lenselink AM, Rosendaal FR, Doggen CJM. Pregnancy, the postpartum period and prothrombotic defects: risk of venous thrombosis in the MEGA study. J Thromb Haemost 2008;6(4): 632-637

4 Sultan AA, West J, Tata LJ, Fleming KM, Nelson-Piercy C, Grainge MJ. Risk of first venous thromboembolism in and around pregnancy: a population-based cohort study. Br J Haematol 2012; 156(3):366-373

5 Panting-Kemp A, Geller SE, Nguyen T, Simonson L, Nuwayhid B, Castro L. Maternal deaths in an urban perinatal network, 19921998. Am J Obstet Gynecol 2000;183(5):1207-1212

6 Brenner B. Haemostatic changes in pregnancy. Thromb Res 2004; 114(5-6):409-414

7 Buchholz T, Thaler CJ. Inherited thrombophilia: impact on human reproduction. Am J Reprod Immunol 2003;50(1):20-32

8 Fawole B, Awolude OA, Adeniji AO, Onafowokan O. WHO Recommendations for the Prevention of Postpartum Haemorrhage: RHL Guideline (last revised: 1 May 2010). The WHO Reproductive Health Library; Geneva: World Health Organization; 2010

9 Al-Zirqi I, Vangen S, Forsen L, Stray-Pedersen B. Prevalence and risk factors of severe obstetric haemorrhage. BJOG 2008;115(10): 1265-1272

10 Voroshilina E, Ovsepyan R, Plotko E, et al. Reference ranges for standard coagulation tests and thrombodynamics assay during normal pregnancy at various gestational ages (article in Russian). Bull RSMU 2015:40-45

11 Réger B, Péterfalvi A, Litter I, et al. Challenges in the evaluation of D-dimer and fibrinogen levels in pregnant women. Thromb Res 2013;131(4):e183-e187

12 Macafee B, Campbell JP, Ashpole K, et al. Reference ranges for thromboelastography (TEG( $\left.\left({ }^{\circ}\right)\right)$ and traditional coagulation tests in term parturients undergoing caesarean section under spinal anaesthesia. Anaesthesia 2012;67(7):741-747

13 Joly B, Barbay V, Borg J-Y, Le Cam-Duchez V. Comparison of markers of coagulation activation and thrombin generation test in uncomplicated pregnancies. Thromb Res 2013;132(3):386-391

14 Ataullakhanov IA, Koltsova EM, Balandina AN, Serebriyskiy II, Vuimo TA, Panteleev MA. Classic and global hemostasis testing in pregnancy and during pregnancy complications. Semin Thromb Hemost 2016;42(7):696-716

15 Reynen E, James P. Von Willebrand disease and pregnancy: a review of evidence and expert opinion. Semin Thromb Hemost 2016;42(7):717-723

16 Kouides PA. Present day management of inherited bleeding disorders in pregnancy. Expert Rev Hematol 2016:1-9
17 James AH, Grotegut C, Ahmadzia H, Peterson-Layne C, Lockhart E. Management of coagulopathy in postpartum hemorrhage. Semin Thromb Hemost 2016;42(7):724-731

18 Huq FY, Kadir RA. Management of pregnancy, labour and delivery in women with inherited bleeding disorders. Haemophilia 2011; 17(Suppl 1):20-30

19 de Moerloose P, Schved JF, Nugent D. Rare coagulation disorders: fibrinogen, factor VII and factor XIII. Haemophilia 2016;22 (Suppl 5):61-65

20 Davies J, Kadir R. The management of factor XI deficiency in pregnancy. Semin Thromb Hemost 2016;42(7):732-740

21 Saracco P, Bagna R, Gentilomo C, et al; Neonatal Working Group of Registro Italiano Trombosi Infantili (RITI). Clinical data of neonatal systemic thrombosis. J Pediatr 2016;171:60-66.e1

22 Soucie JM, Evatt B, Jackson D; The Hemophilia Surveillance System Project Investigators. Occurrence of hemophilia in the United States. Am J Hematol 1998;59(4):288-294

23 Monagle P, Chan AK, Goldenberg NA, et al; American College of Chest Physicians. Antithrombotic therapy in neonates and children: Antithrombotic Therapy and Prevention of Thrombosis, 9th ed: American College of Chest Physicians Evidence-Based Clinical Practice Guidelines. Chest 2012;141(2, Suppl):e737S-e801S

24 Hanmod SS, Jesudas R, Kulkarni R, Chitlur M. Neonatal hemostatic disorders: issues and challenges. Semin Thromb Hemost 2016; 42(7):741-751

25 Andrew M, David M, Adams M, et al. Venous thromboembolic complications (VTE) in children: first analyses of the Canadian Registry of VTE. Blood 1994;83(5):1251-1257

26 van Ommen CH, Heijboer H, van den Dool EJ, Hutten BA, Peters M. Pediatric venous thromboembolic disease in one single center: congenital prothrombotic disorders and the clinical outcome. J Thromb Haemost 2003;1(12):2516-2522

27 van Ommen CH, Sol JJ. Developmental hemostasis and management of central venous catheter thrombosis in neonates. Semin Thromb Hemost 2016;42(7):752-759

28 Bennett A, Chunilal S. Diagnosis and management of deep vein thrombosis and pulmonary embolism in pregnancy. Semin Thromb Hemost 2016;42(7):760-773

29 Creanga AA, Berg CJ, Syverson C, Seed K, Bruce FC, Callaghan WM. Pregnancy-related mortality in the United States, 2006-2010. Obstet Gynecol 2015;125(1):5-12

30 James AH, Jamison MG, Brancazio LR, Myers ER. Venous thromboembolism during pregnancy and the postpartum period: incidence, risk factors, and mortality. Am J Obstet Gynecol 2006; 194(5):1311-1315

31 Scully M. Thrombotic thrombocytopenic purpura and atypical hemolytic uremic syndrome microangiopathy in pregnancy. Semin Thromb Hemost 2016;42(7):774-779

32 Schreiber K, Hunt BJ. Pregnancy and antiphospholipid syndrome. Semin Thromb Hemost 2016;42(7):780-788

33 Cervera R, Piette JC, Font J, et al; Euro-Phospholipid Project Group. Antiphospholipid syndrome: clinical and immunologic manifestations and patterns of disease expression in a cohort of 1,000 patients. Arthritis Rheum 2002;46(4):1019-1027

34 Cohen H, Arachchillage DRJ, Beyer-Westendorf J, Middeldorp S, Kadir R. Direct oral anticoagulants and women. Semin Thromb Hemost 2016;42(7):789-797

35 D'Souza RMD, Silversides CK, McLintock C. Optimal anticoagulation in pregnant women with mechanical heart valves. Semin Thromb Hemost 2016;42(7):798-804 